\section{Case Reports in Oncology}

\title{
A Squamous Cell Carcinoma and a Malignant Fibrous Histiocytoma Developing in a Patient with a Mature Cystic Teratoma
}

\author{
Ali Emre Tahaoglu ${ }^{a} \quad$ Serhat Ege ${ }^{a} \quad$ Mehmet Sait Bakir $^{a} \quad$ Gülbin Saruhan $^{b}$ \\ Serif Aksin ${ }^{a}$ Talip Gul \\ ${ }^{a}$ Saglik Bilimleri University, Gazi Yasargil Research and Training Hospital, Department of \\ Gynecology and Obstetrics, Diyarbakir, Turkey; ${ }^{\text {b}}$ Saglik Bilimleri University, Gazi Yasargil \\ Research and Training Hospital, Department of Pathology, Diyarbakir, Turkey; \\ 'Dicle University, Department of Gynecology and Obstetrics, Dicle, Turkey
}

\section{Keywords}

Cystic teratoma $\cdot$ Squamous cell carcinoma $\cdot$ Fibrous histiocytoma

\begin{abstract}
We present a very rare case of malignant transformation of a benign mature cystic teratoma. The pathology report revealed malignant transformation of both the epithelial and sarcomatous elements of a benign dermoid cyst. To the best of our knowledge, this appears to be the third case of a malignant fibrous histiocytoma and a squamous cell carcinoma developing from a mature cystic teratoma. Malignant transformation of a dermoid cyst is usually diagnosed postmenopausally, but our patient was premenopausal. The etiology and prognosis of malignant transformation of this benign condition remain unknown.
\end{abstract}

(C) 2017 The Author(s)

Published by S. Karger AG, Basel 
 Oncology}

\section{Introduction}

A mature cystic teratoma is the most common ovarian germ cell tumour, occurring in $10-20 \%$ of all ovarian tumours [1]. The frequency of malignant transformation is about $1 \%$, and the most common type of malignant transformation is that to squamous cell carcinoma [2-4]. Malignant melanoma, primary osteosarcoma, dedifferentiated chondrosarcoma, rhabdomyosarcoma, and angiosarcoma arising in dermoid cysts have been reported in the literature [5-9]. A malignant fibrous histiocytoma developing in a mature cystic teratoma is extremely rare; to the best of our knowledge, only eight such cases have been previously reported. This is the third case of a malignant fibrous histiocytoma associated with squamous cell carcinoma exhibiting both epithelial and sarcomatous transformation from a mature cystic teratoma.

\section{Case}

A 42-year-old premenopausal, G3P3-stage woman presented with serious pelvic pain and polymenorrhagic haemorrhage. Upon specular vaginal examination, the vulva and vagina were normal, and no suspicious cervical lesion was observed. A mobile solid, ca. $10 \times 10$ $\mathrm{cm}$ mass was evident upon bimanual examination of the left adnexa. Transvaginal ultrasonography revealed a $106 \times 113$-mm cystic mass mimicking an endometrioma; the unilocular cyst yielded diffuse homogeneous ground-glass echoes (Fig. 1). Pelvic computed tomography revealed a $118 \times 78 \times 85$-mm septate cystic lesion characterised by high lipid content, nodular components, and focal wall calcification (Fig. 2). Only the levels of CA-125 (49.8 U/mL) and CA-19,9 (42.1 U/mL) were elevated. Exploratory laparotomy was performed. The uterus, right adnexa, and ovary were normal; no malignant ascites or peritoneal spread of a malignant tumour was apparent, but a mobile 10 -cm-diameter mass was evident in the left adnexa. The mass was not adherent to other pelvic organs. Left salpingo-ovariectomy was performed, and the mass subjected to frozen sectioning (Fig. 3). The pathologist reported that the mass could not be defined as either malignant or benign; we thus ceased operating, awaiting a final pathology report. No pre- or postoperative complication developed; the patient was discharged.

One month later, the final pathology report confirmed that a squamous cell carcinoma and a malignant fibrous histiocytoma had developed in a mature cystic teratoma. We performed a repeat laparotomy; $40-50 \mathrm{~mL}$ of ascites was aspirated, and the wash cytology was sampled. On the left side, the sigmoid colon, left ureter, and bladder were conglomerated. Pararectal and paravesical fossae were identified, and we performed total abdominal hysterectomy, right salpingo-ovariectomy, tumourectomy, and bilateral pelvic and para-aortic lymph node dissection. About $0.5 \mathrm{~cm}$ of tumour were not removed on the left ureter to avoid damage. A drainage tube was inserted, and the abdominal incision closed. The patient was hospitalised for 4 days, but no complication was observed pre- or postoperatively.

On gross examination, the mass was enclosed and contained greasy material including keratin and hair; haemorrhagic areas were evident in the cystic region. Microscopically, an irregularly thickened necrotic area was apparent. Stratified squamous epithelium, skin cells, cartilage tissue, and ciliated bronchioles epithelium were demonstrated. A welldifferentiated squamous cell carcinoma appears to arise from benign squamous epithelium (Fig. 4, Fig. 5). The cells formed strands, cords, and nests and exhibited pleomorphic hyperchromatic nuclei, eosinophilic cytoplasm, and focal keratinisation. Squamous cell carcinoma 


\section{Case Reports in Oncology}

showed pancytokeratin and P63 positivity. Mature adipose tissue and a ciliated columnar epithelium surrounded the cyst walls. Multinucleated giant cells, scattered cells that were polygonal-to-spindle-like in shape (and markedly pleomorphic in their characteristics), and unusual tumour cells were evident (Fig. 6, Fig. 7). Multiple atypical mitotic figures and a significant multinucleated giant cell reaction were apparent. The tumour cells were negative for desmin, smooth muscle actin, and myogenin, but positive for CD68 (Fig. 8). These features were consistent with a diagnosis of a malignant fibrous histiocytoma and squamous cell carcinoma, arising from a mature cystic teratoma. The two components were spatially separated.

The 2-week follow-up visit was uncomplicated, but the 2-cm abdominal incision gap lay only $5 \mathrm{~cm}$ below the umbilicus. Two stitches were placed. After the 1-month follow-up, the patient was referred to our medical oncology department because no complications were evident. Platin-based chemotherapy was scheduled. At the 3-month follow-up, the patient complained of serous flow through the area of secondary suturing. A plastic surgeon was consulted. Positron emission tomography-CT was performed; a 6-cm-thick metastatic area was observed near the incision; this had spread to the musculus rectalis facia. The abdominal incision was enlarged, a skin biopsy was taken, and skin-thickness grafting performed. The pathology report on the skin sample revealed metastasis of the squamous cell carcinoma. At the 1-year follow-up, the patient remains alive.

\section{Discussion}

Mature cystic teratomas, also termed dermoid cysts, contain tissues derived from all three germ-cell layers, all of which can give rise to malignant tumours, although such tumours develop in only $0.17-2 \%$ of cases [10]. The most common cystic malignant transformation is squamous cell carcinoma. Although dermoid cysts have three germ layers, sarcomatous differentiation is very rare. Malignant fibrous histiocytoma is a sarcomatous tumour and is the most common soft-tissue sarcoma in adults. The origin of tumour cells remains contentious, but it is clear that histiocytes do not give rise to tumours [11]. Araujo et al. [12] showed that HPV infection is a risk factor for malignant transformation of dermoid cysts into squamous cell carcinomas in young patients; molecular studies are required to confirm whether HPV plays a role in malignant transformation. The risk factors for dermoid cyst malignancy include patient age ( $>45$ years), tumour diameter, tumour growth rate, imaging features, and elevated serum levels of various factors [13, 14].

Malignant transformation of dermoid cysts is rare; neither the risk factors for transformation nor the optimal treatment is clear. The chosen treatment is usually that offered to patients with epithelial ovarian cancer [15]. Complete surgery and adjuvant chemotherapy are often prescribed; any role for radiotherapy remains unclear $[15,16]$. In our patient, we performed complete surgery and platinum-based chemotherapy for 6 cycles, but despite that treatment, incision metastasis was observed after 2 months. In conclusion, malignant fibrous histiocytomas and squamous cell carcinomas developing from dermoid cysts are extremely rare. The etiology and prognosis of malignant transformation of benign teratoma is variable and the underlying mechanism remains unknown. 


\section{Statement of Ethics}

Informed consent of the patient was obtained to publish this case.

\section{Disclosure Statement}

The authors have no conflicts of interest to declare.

\section{References}

1 Ayhan A, Bükülmez O, Genç C, Karamürsel BS, Ayhan A: Mature cystic teratomas of the ovary: case series from one institution over 34 years. Eur J Obstet Gynecol Reprod Biol 2000;88:153-157.

-2 Vercellini P, Chapron C, De Giorgi O, Consonni D, Frontino G, Crosignani PG: Coagulation or excision of ovarian endometriomas? Am J Obstet Gynecol 2003;188:606-610.

3 Mecke H, Savvas V: Laparoscopic surgery of dermoidcysts - intraoperative spillage and complications. Eur J Obstet Gynecol Reprod Biol 2001;96:80-84.

-4 Ferrari MM, Mezzopane R, Bulfoni A, Grijuela B, Carminati R, Ferrazzi E, Pardi G: Surgical treatment of ovarian dermoid cysts: a comparison between laparoscopic and vaginal removal. Eur J Obstet Gynecol Reprod Biol 2003;109:88-91.

5 Kudva R, Ayachit GS, Ayachit A: Malignant melanoma arising in an ovarian mature cystic teratoma - a rare entity. J Clin Diagn Res 2015;9:ED14-6.

-6 Fadere 0, Bossuyt V, Martel M, et al: Primary osteosarcoma of ovary: a case report and literature review. Int J Gynecol Pathol 2007;26:21-25.

7 Yasunga M, Saito T, Eto T, et al: Dedifferentiated chondrosarcoma arising in a mature cystic teratoma of the ovary: a case report and review of the literature. Int J Gynecol Pathol 2011;30:391-394.

8 Kefeli M, Kandemir B, Akpolat I, et al: Rhabdomyosarcoma arising in a mature cystic teratoma with contralateral serous carcinoma: case report and review of the literature. Int J Gynecol Pathol 2009:28:372-375.

-9 Conteras AL, Malpica A: Angiosarcoma arising in mature cystic teratoma of the ovary: a case report and review of the literature. Int J Gynecol Pathol 2009;28:453-457.

10 Mandal S, Badhe BA: Malignant transformation in a mature teratoma with metastatic deposits in the omentum: a case report. Case Rep Pathol 2012;2012:568062.

11 Fletcher CD: Malignant fibrous histiocytoma? Histopathology 1987;11:433-437.

-12 Araujo IB, Pinheiro MV, Zanvettor PH, Studart EJ, Filho DF, Coupland SE: High frequency of malignant transformation of ovarian mature teratoma into squamous cell carcinoma in young patients in northeast Brazil. Int J Gynecol Pathol 2016;35:176-184.

13 Dos Santos L, Mok E, Iasonos A, Park K, Soslow RA, Aghajanian C, Alektiar K, Barakat RR, Abu-Rustum NR: Squamous cell carcinoma arising in mature cystic teratoma of the ovary: a case series and review of the literature. Gynecol Oncol 2007;105:321-324.

14 Al-Rayyan ES, Duqoum WJ, Sawalha MS, Nascimento MC, Pather S, Dalrymple CJ, Carter JR: Secondary malignancies in ovarian dermoid cyst. Saudi Med J 2009;30:524-528.

15 Hackethal A, Brueggmann D, Bohlmann MK, Franke FE, Tinneberg HR, Münstedt K: Squamous-cell carcinoma in mature cystic teratoma of the ovary: systematic review and analysis of published data. Lancet Oncol 2008;9:1173-1180.

16 Hurwitz JL, Fenton A, McCluggage WG, McKenna S: Squamous cell carcinoma arising in a dermoid cyst of the ovary: a case series. BJOG 2007;114:1283-1287. 


\section{Case Reports in Oncology}

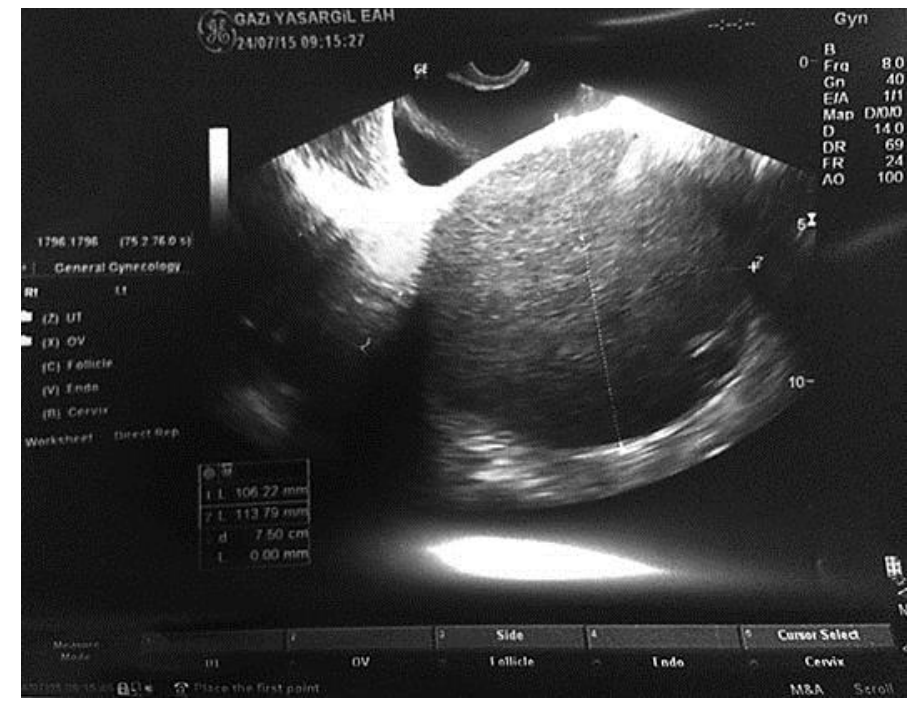

Fig. 1. Ultrasonographic view.

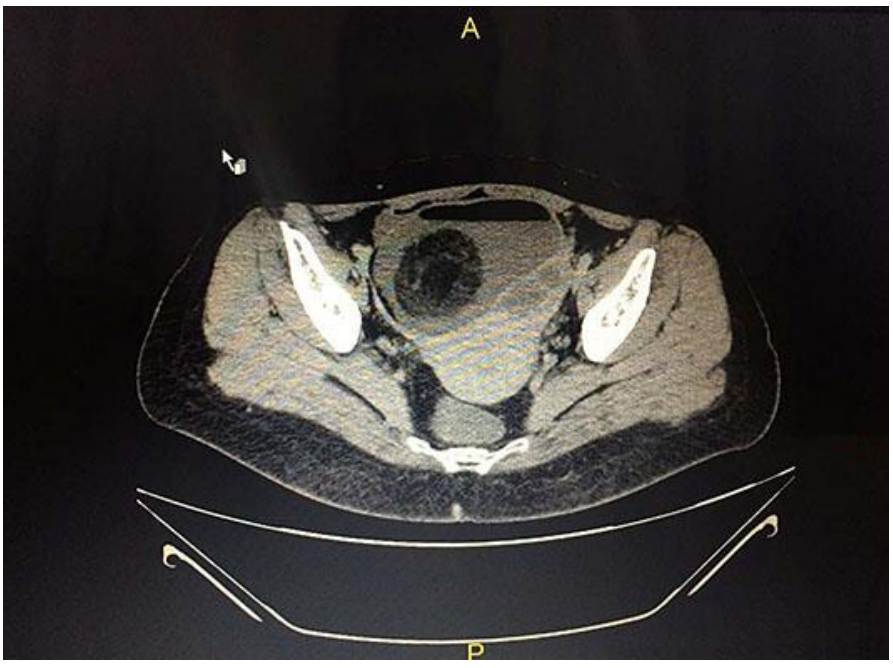

Fig. 2. Computerized tomography scan.

Fig. Computerized tomography scan. 


\section{Case Reports in Oncology}

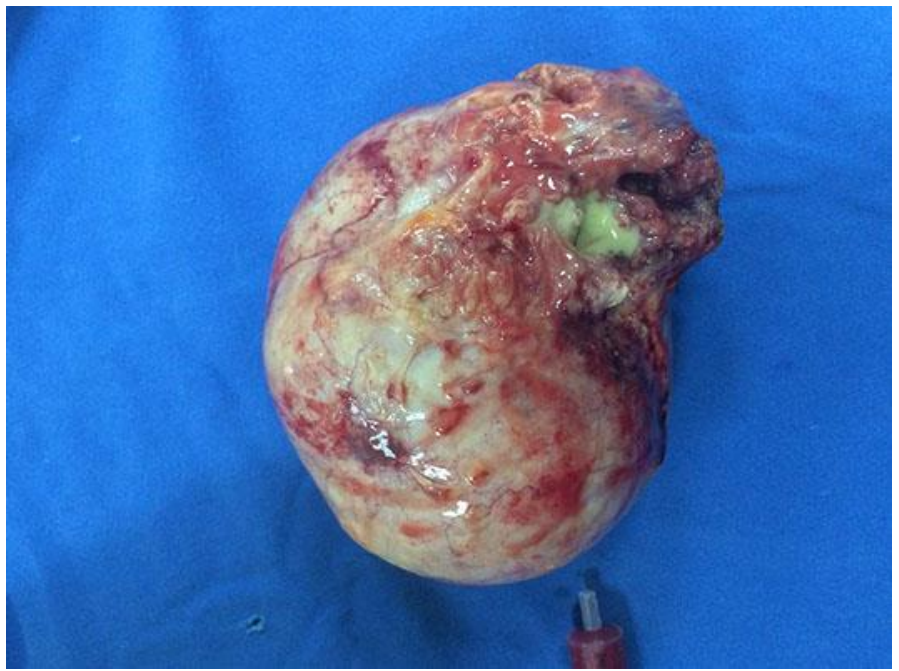

Fig. 3. Frozen section material.

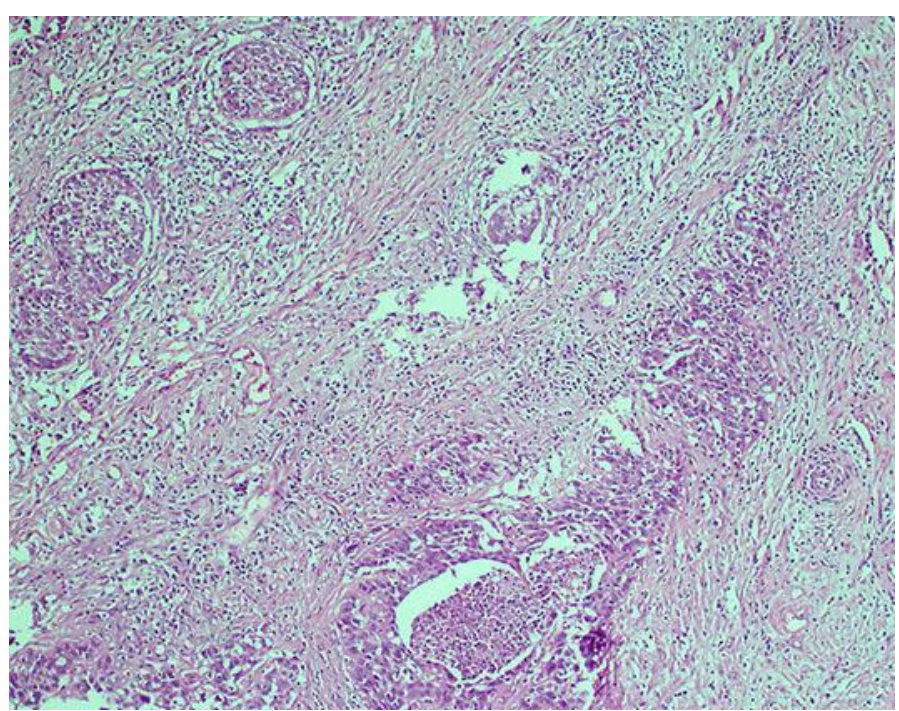

Fig. 4. Foci of squamous cell carcinoma. HE. $\times 5$. 


\section{Case Reports in Oncology}

Tahaoglu et al: A Squamous Cell Carcinoma and a Malignant Fibrous Histiocytoma Developing in a Patient with a Mature Cystic Teratoma

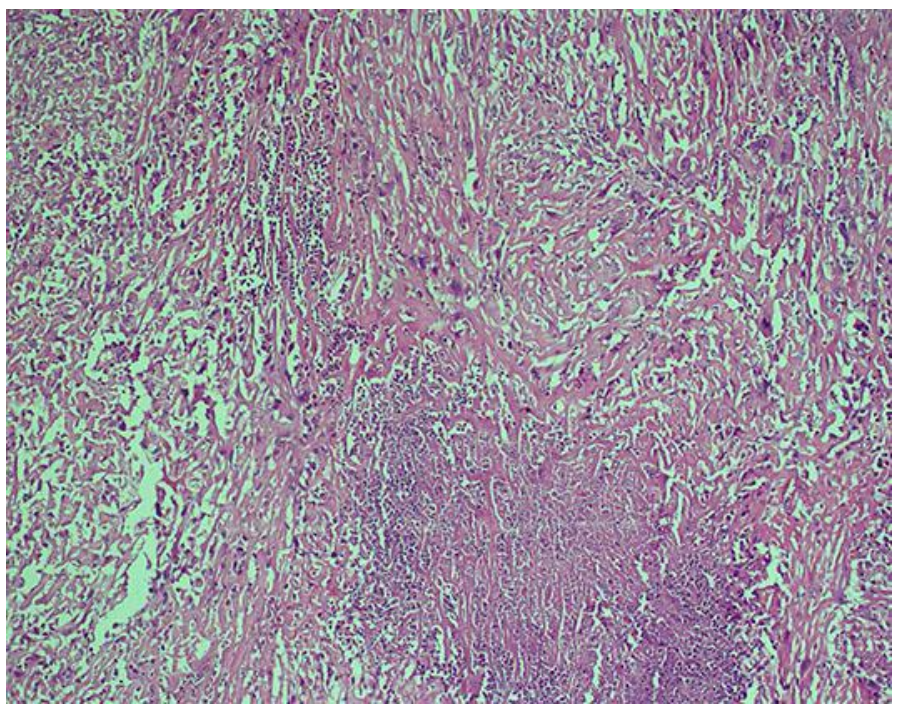

Fig. 5. Dense inflammation, abscess formation, and atypical mitosis with fibroblastic activity.

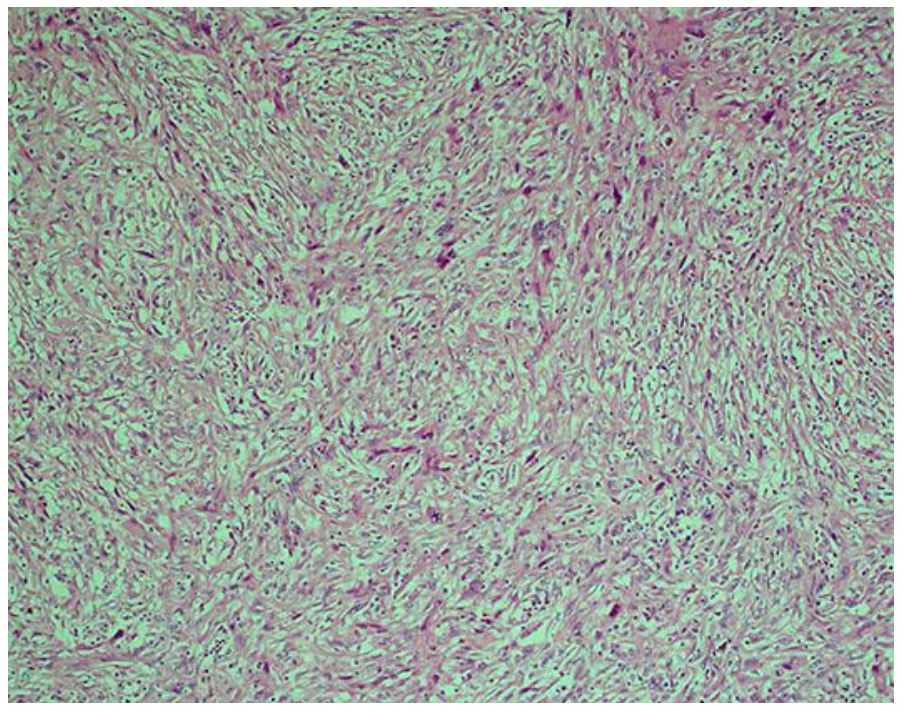

Fig. 6. Atypical mitotic figures and giant cells with storiform pattern-clustered and scattered polygonal cells to spindle cells with markedly pleomorphic characteristics (inflammatory cell infiltration). 


\section{Case Reports in Oncology}

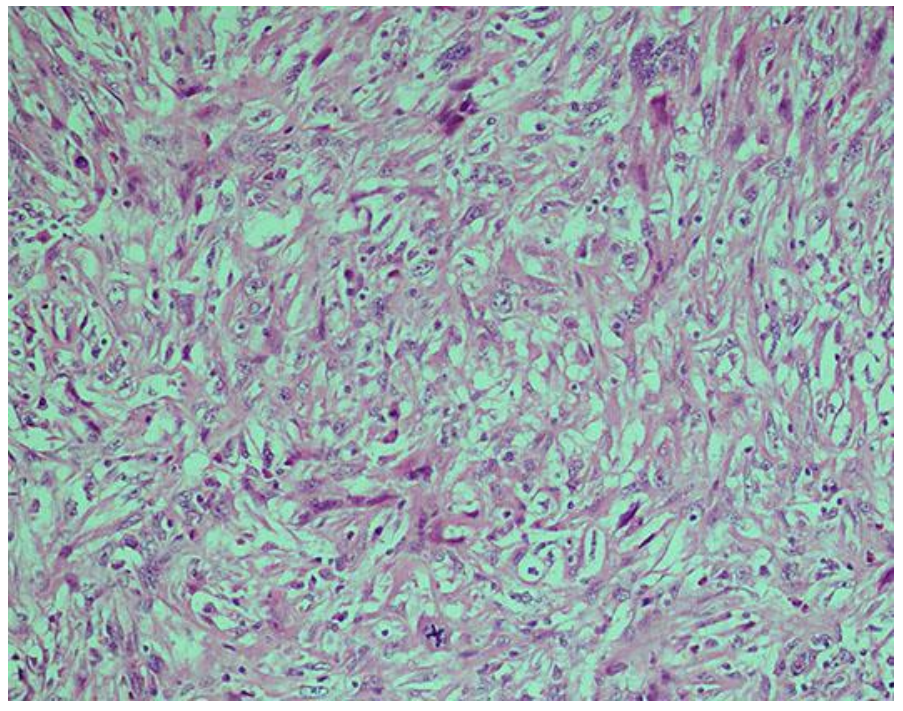

Fig. 7. Atypical tetrapolar mitosis and giant cell formation.

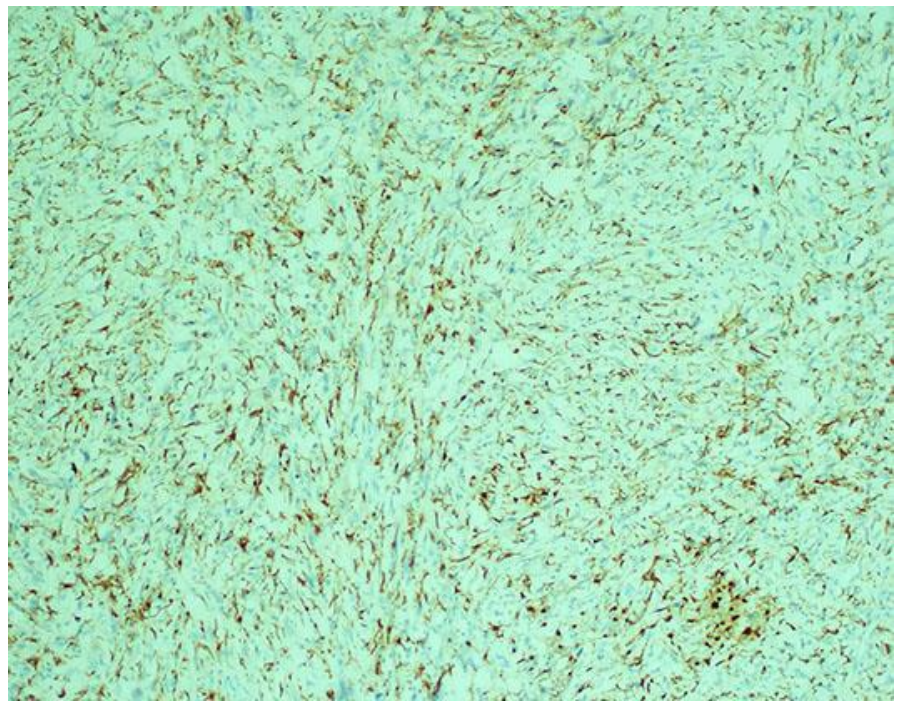

Fig. 8. Cells show CD68 positivity on immunohistochemistry. 